DOI: https://doi.org/10.24127/ajpm.v10i2.3091

\title{
PENGEMBANGAN MEDIA PEMBELAJARAN POP UP BOOK BERBASIS DISCOVERY LEARNING MEMBUKTIKAN LUAS DAN KELILING LINGKARAN
}

\author{
Timbul Yuwono $^{{ }^{*}}$, Arik Dwi Indah Ningrum², Djoko Adi Susilo ${ }^{3}$ \\ ${ }^{1,2,3}$ Universitas Kanjuruhan Malang, Malang, Indonesia \\ *Corresponding author \\ E-mail: $\quad$ timbulyuwono@unikama.ac.id $^{* 1)}$ \\ arik63978@gmail.com $^{2)}$ \\ djokoadi@unikama.ac.id $^{3)}$
}

Received 10 September 2020; Received in revised form 14 January 2021; Accepted 28 June 2021

\begin{abstract}
Abstrak
Tujuan penelitian ini adalah adalah untuk memperoleh media pembalajaran pop up book yang valid, praktis dan efektif dalam pembelajaran matematika. Peneliti menggunakan Model ADDIE dengan instrumen, yaitu angket dan post test berupa jawaban soal evaluasi untuk mengetahui keefektifan media. Uji coba dilakukan di SMP Taman Siswa Kesamben Blitar dan SMP PGRI 02 Kesamben Blitar. Berdasarkan hasil validasi darii validator memperoleh kriteria valid dari ahli materi memperoleh skor 3,58, ahli media memperoleh skor 3,43, dan validator dua ahli pembelajaran memperoleh skor 3,45 dengan kriteria valid. Kepraktisan media diperoleh dari hasil uji coba lapangan terbatas skor kepraktisan (Pk) 3,32 dengan kriteria praktis. Uji coba lapangan luas memperoleh skor kepraktisan (Pk) 3,37 dengan kriteria praktis. Keefektifan media dari siswa uji lapangan terbatas $100 \%$, Keefektifan media dari tes siswa pada uji lapangan terbatas, yaitu $100 \%$, sedangkan uji lapangan luas, yaitu 92,8\% dengan kriteria efektif. Dilihat dari skornya, bahwa media hasil pengembangan dapat digunakan secara efektif dalam pembelajaran matematika.
\end{abstract}

Kata kunci: Discovery learning; pop up book.

\begin{abstract}
The purpose of this study was to obtain a valid, practical and effective pop up book learning medium in learning mathematics. Researchers used the ADDIE Model with instruments, namely questionnaires and post tests in the form of answers to evaluation questions to determine the effectiveness of the media. The trial was conducted at SMP Taman Siswa Kesamben Blitar and SMP PGRI 02 Kesamben Blitar. Based on the validation results, the validator obtained valid criteria from the material expert obtaining a score of 3.58, the media expert obtained a score of 3.43, and the validator of two learning experts obtained a score of 3.45 with valid criteria. The practicality of the media was obtained from the results of a limited field trial of a practicality score (Pk) of 3.32 with practical criteria. The broad field trial obtained a practicality score $(P k)$ of 3.37 with practical criteria. The effectiveness of the media from the students in the field test was limited to $100 \%$, the effectiveness of the media from the student tests on the limited field test, namely $100 \%$, while the broad field test was $92.8 \%$ with effective criteria. Judging from the score, that the developed media can be used effectively in learning mathematics.
\end{abstract}

Keywords: Discovery learning; pop up book.

This is an open access article under the Creative Commons Attribution 4.0 International License

\section{PENDAHULUAN}

Fungsi media pembelajaran adalah membawa pesan-pesan atau informasi yang tujuan pembelajaran
(Devi \& Maisaroh, 2017). Fungsi media pembelajaran sangatlah penting dengan memberi rasa minat dan menghilangkan rasa bosan serta dapat tercapainya 
tujuan pembelajaran yang aktif dan produktif. Media pembelajaran selain membatu guru dalam menyampaikan informasi juga dapat memberi rasa tertarik pada siswa (Murdiyanto \& Mahatama, 2014) Rasa tertarik pada siswa menimbulkan minat siswa dalam proses pembelajaran seperti media pembelajaran berbentuk pop up book.

$$
\text { Pembelajaran menggunakan }
$$

media pop up book berkaitan erat dengan pemecahan masalah, penalaran matematis dan kemampuan representasi matematisnya. Kusrianto dkk. (2016) menyatakan pembelajaran dengan menggunakan model CORE berbantuan pop up book terbukti efektif terhadap kemampuan siswa pada aspek representasi matematis khususnya pada materi kubus dan balok, Menurut Fitriyah (2018) kemampuan pemecahan masalah matematika siswa dengan model Base Learning berbantuan pop up book lebih baik daripada yang tidak menggunakan pop up book. Amalia dkk., (2020) menyatakan bahwa media pop up book memiliki efek sangat kuat dalam meningkatkan kemampuan pemecahan masalah matematis siswa. Kemampuan penalaran matematis siswa kelas eksperimen menggunakan bahan ajar matematika berbasis Contextual Teaching and Learning berbantuan Pop Up Book lebih baik dari pada kemampuan penalaran matematis siswa kelas control yang tidak menggunakan pop up book (Widya dkk., 2020). Berdasarkan pendapat dan hasil penelitian diatas, sehingga dapat disimpulkan bahwa pembelajaran menggunakan media pop up book dapat meningkatkan pemecahan masalah, kemampuan representasi dan penalaran matematisnya lebih baik dengan menggunakan model pembelajaran yang sesuai.
Model pembelajaran yang digunakan pada penelitian ini yaitu, menggunakan discovery learning. Berdasarkan Svinicki (1998) karakteristik utama pembelajaran penemuan (discovery learning) dengan menghubungkannya dengan teori kognitif, yaitu penekanan pada pembelajaran, pengembangan pembelajaran bermakna, dan kemampuan untuk mengubah sikap siswa (subjek) sebagai pemecah masalah. Siswa dituntun untuk memecahkan masalah dan pembelajaran matematika.

$\begin{array}{cc}\text { Pembelajaran } & \text { menggunakan } \\ \text { discovery learning mempunyai }\end{array}$ pengaruh lebih besar, karena melibatkan langsung siswa dalam pemecahan masalah sedangkan guru sebagai fasilitator. Batubara (2020) menyatakan hasil belajar pengembangan silabus pembelajaran matematika mahasiswa melalui model pembelajaran guided discovery learning lebih tinggi daripada peningkatan hasil belajar mahasiswa yang tidak memperoleh model pembelajaran guided discovery learning. Sutarka (2020) menyatakan bahwa model pembelajaran discovery dan media rekaman video dapat meningkatkan motivasi belajar siswa pada saat pandemik. Demikian juga dengan penggunaan pembelajaran dengan menggunakan pop up book praktis dan efektif. Menurut Ikbal dkk (2020) bahwa pengembangn modul pembelajaran IPA Fisika Berbasis Popup Book memenuhi kriteria valid, parktis, dan efektif.

Permasalahan yang ada pada dua sekolahan khususnya kelas VIII yaitu SMP Taman Siswa Kesamben Blitar, yaitu siswa cenderung mendengarkan penjelasan dari guru tanpa melakukan kegiatan yang seperti pembuktian. Sedangkan pada siswa 
SMP PGRI 02 Kesamben Blitar siswa tidak fokus mendengarkan penjelasan guru.

Penelitian pengembangan ini sangat bermanfaat membantu guru dalam pembuktikan luas dan keliling lingkaran. Media ini dihasilkan dapat berfungsi sebagai alat peraga dalam pembuktikan luas dan keliling lingkaran untuk siswa kelas VIII SMP.

Penelitian terdahulu dari Hendri \& Kenedi (2018) tentang suatu alat atau perangkat yang memakai model pembelajaran discovery learning pada kelas VIII matematika SMP. Perangkat yang dikembangkan memiliki sintak pembelajaran discovery learning, di dalam perangkat pembelajaran terdapat pembuktian dan belum adanya soal latihan siswa yang berguna untuk melatih komunikasi. Penelitian Baiduri dkk (2019), yaitu cover, pokok kegiatan yang terdiri dari 6 halaman dengan kertas F4, penomoran halaman menonjol dibagian luar supaya terlihat oleh pembaca, bagian isi terdapat alur pengisian temuan terbimbing (discovery learning) Hasil penelitian menunjukkan bahwa discovery learning efektif dan efesien dalam pembelajaran matematika.

Oleh karena itu, penelitian ini penting untuk mengembangkan media pembelajaran pop up book yang valid, praktis dan efektif dalam pembelajaran matematika berbasis discovery learning untuk membuktikan luas dan keliling lingkaran..

\section{METODE PENELITIAN}

Penelitian pengembangan model ADDIE ini diadaptasi dari Permana \& Sari, 2018) penelitian ini dilakukan di dua sekolah menengah pertama. Tahapan yang dilakukan ada 5 tahapan. Tahap pertama analisis, yaitu kebutuhan dan karakteristik siswa yang akan menjadi target pengguna pop up book. Tahap kedua perencanaan yaitu merencanakan media yang diharapkan, mengumpulkan bahan-bahan yang diperlukan dalam pembuatan media serta Instrumen yang dibutuhkan. Tahap ketiga ini meliputi validasi dan revisi media untuk terwujudnya tujuan. Validasi digunakan untuk mengetahui kevalidan dengan menggunakan validator ahli materi dan media. Komentar perbaikan merupakan revisi dari semua validator. Tahap keempat tahap implementasi ini media yang sudah valid di uji cobakan pada siswa kelas VIII SMP Taman Siswa Kesamben Blitar dan uji coba lapangan luas pada siswa kelas VIII SMP PGRI 02 Kesamben Blitar. Selama uji coba siswa mengerjakan soal evaluasi yang ada dalam pop up book berbasis discovery learning untuk mengetahui tingkat keefektifan media, selanjutnya siswa mengisi angket respon yang diberikan untuk mengetahui kepraktisan media setelah melakukan uji coba lapangan, selanjutnya peneliti melakukan wawancara kepada guru matematika kelas VIII SMP. Tahap kelima yaitu evaluasi pada setiap tahap, sehingga penyempurnaan bisa dilakukan pada setiap tahap, sehingga evaluasi ini selalu berkesinambungan untuk menghasilkan media yang valid, praktis dan efektif.

Instrumen pengumpulan data diperoleh dari pedoman wawancara guru dan siswa untuk memperoleh data kualitatif . Instrumen penilaian media berupa angket. Skor penilain media seperti pada Tabel 1 .

Tabel 1. Skor penilain media

\begin{tabular}{clc}
\hline No & \multicolumn{1}{c}{ Kriteria penilaian } & Skor \\
\hline 1 & Sangat Setuju (SS) & 4 \\
2 & Baik/Setuju (B/S) & 3 \\
3 & Cukup Baik/Kurang Setuju (CB/KS & 2 \\
4 & Kurang Baik/Tidak setuju (KB/KS) & 1 \\
\hline
\end{tabular}


Instrumen tes berupa soal evaluasi yang berjumlah 3 buah soal, dari jawaban siswa dianalisis untuk mengetahui tingkat keefektifan. Pedoman perhitungan uji kevalidan menggunakan rumus sebagai berikut:

$$
l_{i}=\frac{\sum_{j=1}^{n} V_{j, i}}{n}
$$

Dengan $\sum_{j=1}^{n} V_{j, i}$ adalah Jumlah nilai validator ke- $j$ untuk indikator ke- $i$ dan $n$ adalah banyak validator. Setelah mendpat rata-erata hasil validasi dalam setia indikator $\left(l_{i}\right)$, selanjutnya mencari skor kevalidan $(\mathrm{V})$ dengan rumus:

$$
V=\frac{\sum_{i=1}^{n} l_{i}}{m} \quad \ldots \ldots
$$

Keterangan:

$$
\begin{aligned}
\sum_{i=1}^{n} l_{i}= & \begin{array}{l}
\text { Jumlah rata-rata nilai } \\
\text { hasil validasi pada } \\
\text { indikator ke- } i
\end{array} \\
m= & \text { Banyak indikator }
\end{aligned}
$$

\begin{tabular}{|c|c|c|c|}
\hline No & Nilai & Kriteria & Keterangan \\
\hline 1 & $V=4,00$ & $\begin{array}{l}\text { Sangat } \\
\text { Valid }\end{array}$ & Tidak revisi \\
\hline 2 & $3,26 \leq V<4,00$ & Valid & Tidak revisi \\
\hline 3 & $2,51 \leq V<3,25$ & $\begin{array}{l}\text { Cukup } \\
\text { Valid }\end{array}$ & $\begin{array}{l}\text { Revisi } \\
\text { Sebagian }\end{array}$ \\
\hline 4 & $1,76 \leq V<2,50$ & $\begin{array}{l}\text { Kurang } \\
\text { Valid }\end{array}$ & $\begin{array}{l}\text { Revisi } \\
\text { Sebagian }\end{array}$ \\
\hline 5 & $1,00 \leq V<1,75$ & $\begin{array}{l}\text { Tidak } \\
\text { Valid }\end{array}$ & $\begin{array}{l}\text { Revisi } \\
\text { semua }\end{array}$ \\
\hline
\end{tabular}

Dari hasil uji coba kevalidan selanjutnya ditentukan kriteria seperti pada Tabel 2.

Tabel 2. Kriteria validasi

Teknik kepraktisan diperoleh dengan pedoman rumus:

$$
l_{i}=\frac{\sum_{j=1}^{n} O_{j, i}}{n} \quad \cdots \cdots
$$

Dengan $\sum_{j=1}^{n} O_{j, i}$ merupakan Jumlah nilai siswa ke- $j$ untuk indikator ke- $i$ dan $n$ yaitu banyak siswa yang di uji coba. Setelah mendapatakan rata-rata nilai hasil uji kepraktisan dari angket respon siswa pada setiap indikator $\left(l_{i}\right)$ selanjutnya menghitung skor kepraktisan $(\mathrm{Pk})$ dengan rumus:

$$
P_{k}=\frac{\sum_{i=1}^{n} l_{i}}{m} \quad \ldots \ldots
$$

Dengan $\sum_{i=1}^{n} l_{i}$ jumlah rata-rata nilai hasil uji kepraktisan pada indikator ke- $i$ dan $n$ banyak indikator. Hasil perhitungan skor kepraktisan (Pk) seperti pada Tabel 3 .

Tabel 3. Kriteria kepraktisan

\begin{tabular}{clll}
\hline No & Nilai & Kriteria & Keterangan \\
\hline 1 & $P_{k}=4,00$ & $\begin{array}{l}\text { Sangat } \\
\text { Praktis }\end{array}$ & Tidak revisi \\
2 & $3,25 \leq P_{k}<4,00$ & Praktis & Tidak revisi \\
3 & $2,50 \leq P_{k}<3,24$ & $\begin{array}{l}\text { Cukup } \\
\text { Praktis }\end{array}$ & $\begin{array}{l}\text { Revisi } \\
\text { Sebagian }\end{array}$ \\
4 & $1,75 \leq P_{k}<2,49$ & $\begin{array}{l}\text { Kurang } \\
\text { Praktis }\end{array}$ & $\begin{array}{l}\text { Revisi } \\
\text { Sebagian }\end{array}$ \\
& & $\begin{array}{l}\text { Tidak } \\
\text { Praktis }\end{array}$ & Revisi Total \\
\hline
\end{tabular}

Teknik data keefektifan dari pengerjakan soal evaluasi yang selesai dikerjakan siswa, selajutnya dihitung persentase dengan pedoman rumus:

$$
E=\frac{x}{n} \times 100 \% \quad \ldots \ldots
$$

Dengan $x$ banyak siswa dengan nilai > 75 dan $n$ adalah jumlah siswa. Setelah menghitung presentase ketuntasan (E) dilihat tingkat keefektifan, jika presentase mendapatkan nilai $\geq 75 \%$ diatas ketuntantasan minimal (KKM) yang ditetapkan oleh sekolah.

\section{HASIL DAN PEMBAHASAN}

1. Tahap analisis yang dilakukan pada saat pra penelitian di ketahui berdasarkan hasil wawancara dengan guru pengampu mata pelajaran 
matematika didapatkan kurangnya daya ingatan siswa terhadap rumus keliling dan luas lingkaran dan semangat belajar siswa yang lemah, karena proses pembelajaran hanya sebatas penjelasan, latihan soal dan pemberian tugas pekerjaan rumah.

2. Tahap perancangan (design) merupakan penyusunan kerangka dan ide dalam pembuatan media $p o p$ up. Penyusunan desain agar peneliti memiliki gambaran tentang tampilan dan isi pada media pop up book yang akan di buat. Pop up book yang dikembangkan bertujuan untuk memudahkan dan menambahkan ketertarikan siswa dalam proses pembelajaran. Instrumen yang digunakan berupa pedoman wawancara dan angket (kuesioner) yang disusun untuk mengevaluasi media yang telah dibuat. Penyusunan instrumen diberikan kepada validator ahli materi, ahli media dan ahli pembelajaran untuk menguji kelayakan media pembelajaran dan angket diberikan kepada siswa untuk mengetahui kepraktisan media pembelajaran

3. Tahap pengembangan (development) merupakan tahap realisasi rancangan-rancangan yang telah dibuat di tahap sebelumnya. Setelah tahap pembuatan selesai, media pop up book divalidasikan ke ahli media dan ahli materi, serta ke guru matematika sebagai ahli pembelajaran untuk kelayakan sebelum di uji cobakan.

4. Tahap (implementation)

Implementasi pelaksanaan uji coba media pop up book sebanyak dua kali, uji coba yang pertama merupakan uji coba lapangan terbatas dan dan uji coba kedua merupakan uji coba lapangan luas untuk melihat kepraktisan dan keefektian media pop up book yang digunakan

5. Tahap evaluasi (evaluation) merupakan perbaikan hasil penelitian dari validator dan respon siswa. Semua saran dan perbaikan yang dilakukan terhadap media pop up book yang dikembangkan direvisi dengan baik

\section{Hasil Uji Kevalidan}

1. Hasil Validasi Ahli Meteri.

Merupakan satu validator/dosen matematika Universitas Kanjuruhan Malang hasilnya seperti pada Tabel 4.

Tabel 4. Hasil validasi ahli materi

\begin{tabular}{llcc}
\hline No & Aspek Isi & $\begin{array}{c}\text { Jumlah } \\
\text { Nilai }\end{array}$ & $\begin{array}{c}\text { Rata- } \\
\text { rata }\end{array}$ \\
\hline 1 & Kualitas isi & 29 & 3,62 \\
2 & Kualitas & 14 & 3,4 \\
& Pembelajaran & & \\
\hline & Rata-rata(v) & 43 & 3,58 \\
\hline
\end{tabular}

Berdasarkan Tabel 4 bahwa media pop up book pada aspek kualitas isi dan kualitas pembelajaran masingmasing memperoleh nilai rata rata 3,62 dan 3,4 dengan kriteria valid. Skor seluruh aspek mendapat skor rata-rata 3,58 dengan kriteria valid. Sehingga, media pop up book yang dikembangkan valid dan tidak perlu dilakukan revisi materi.

\section{Hasil Validasi Ahli Media.}

Hasil ahli media validator/dosen matematika Universitas Kanjuruhan Malang seperti pada Tabel 5.

Tabel 5. Hasil validasi ahli media

\begin{tabular}{llcc}
\hline No & \multicolumn{1}{c}{ Aspek } & $\begin{array}{c}\text { Jumlah } \\
\text { Nilai }\end{array}$ & $\begin{array}{c}\text { Rata- } \\
\text { rata }\end{array}$ \\
\hline 1 & Kualitas isi dan tujuan & 10 & 3,33 \\
2 & Kemudahan & 15 & 3,75 \\
3 & Tampilan & 19 & 3,16 \\
4 & Petunjuk Penggunaan & 11 & 3,66 \\
\hline & Rata-rata (v) & 55 & 3,43 \\
\hline
\end{tabular}


Berdasarkan Tabel 5 bahwa media pop up book pada aspek Kualitas Isi dan Tujuan mendapat nilai rata rata 3,33 dengan kriteria valid, pada aspek Kemudahan mendapat nilai rata-rata 3,75 dengan kriteria valid, pada aspek Tampilan mendapat nilai rata rata 3,16 dengan kriteria valid, pada aspek Petunjuk Penggunaan mendapat nilai rata-rata 3,66 dengan kriteria valid. Skor seluruh aspek mendapat skor ratarata 3,44 dengan kriteria valid. Sehingga media pop up book yang dikembangkan valid dan tidak perlu dilakukan revisi medianya .

\section{Hasil Validasi ahli Pembelajaran.}

Hasil validasi ahli pembelajaran berasal dari guru matematika, terdapat 2 guru matematika dengan sekolah berbeda yaitu di SMP Taman Siswa Kesamben Blitar dan SMP PGRI 02 Kesamben Blitar seperti pada Tabel 6.

Tabel 6. Hasil validasi ahli pembelajaran

\begin{tabular}{llcc}
\hline No & \multicolumn{1}{c}{ Aspek } & $\begin{array}{c}\text { Jumlah } \\
\text { nilai }\end{array}$ & $\begin{array}{c}\text { Rata- } \\
\text { rata }\end{array}$ \\
\hline 1 & Isi & 20 & 3,33 \\
2 & Kualitas Pembelajaran & 7 & 3,50 \\
3 & Interaksi & 14 & 3,5 \\
4 & Tampilan & 20 & 3,33 \\
5 & Kemudahan & 8 & 4,00 \\
\hline & Rata-rata (v) & 55 & 3,45 \\
\hline
\end{tabular}

Berdasarkan Tabel 6, diperoleh hasil bahwa media pop up book pada aspek: Kualitas Pembelajaran, Interaksi, Tampilan dan Kemudahan, skor seluruhnya aspek mendapat skor ratarata 3,45, Sehingga, media pop up book yang dikembangkan valid dan tidak perlu dilakukan revisi. Berdasarkan uji coba kevalidan di atas memperoleh validasi dengan krriteria valid tanpa revisi. Menurut Safri dkk., (2017) media dikatakan layak digunakan dilihat dari skor validasi. Skor semua validasi menunjukkan valid, maka media dengan dapat dikatakan layak.

\section{Hasil Uji Kepraktisan}

Hasil kepraktisan di peroleh dari angket respon siswa. Sekolah yang diteliti berada di Kecamatan Kesamben, Blitar. Tempat untuk uji coba lapangan terbatas di rumah siswa kelas VIII SMP Taman Siswa. Penelitian dilaksanakan selama 2 hari. Kepraktisan lapangan disajikan di Tabel 7.

Tabel 7. Hasil uji coba lapangan terbatas

\begin{tabular}{cccc}
\hline No & Aspek & Jumlah Nilai & Skor Pk \\
\hline 1 & Tampilan & 281 & 3,34 \\
2 & Materi & 236 & 3,37 \\
3 & Bahasa & 98 & 3,50 \\
\hline Skor & Kepraktisan & 55 & 3,37 \\
\hline
\end{tabular}

Hasil dari uji lapangan luas pada Tabel 7 diperoleh jumlah nilai 615 dan skor kepraktisan (Pk) diperoleh 3,37 dengan kriteria praktis. Sehingga dari analisis data kepraktisan dengan uji coba lapangan terbatas dan uji coba lapangan luas diperoleh hasil yang memenuhi kriteria praktis, yang artinya media mudah digunakan oleh siswa dalam menyerap materi pembelajaran. Hal ini sesuai dengan pendapat Ramdhani \& Muhammadiyah (2015) bahwa fungsi media untuk memudahkan siswa memahami materi, menimbulkan rasa minat dan tidak bosan dalam proses pembelajaran.

\section{Hasil Uji Coba Keefektifan}

Keefektifan bersumber dari jawaban soal yang dikerjakan oleh siswa. Uji coba lapangan terbatas memeperoleh presentase 100\% karena dari seluruh siswa yang diteliti mendapatkan nilai $\geq 75$. Jadi uji coba media mendapatkan kriteria efektif. Uji coba lapangan luas memiliki subjek 15 siswa dengan 1 orang siswa pindah sekolah, sehingga subjek menjadi 14 siswa. Uji kepraktisan pada lapangan 
luas pemperoleh presentase sebesar $92,8 \%$ sebanyak 13 orang siswa dari 14 orang siswa mendapatakan $\geq 75$. Hasil uji coba lapangan terbatas maupun luas memperoleh perbedaan sebanyak $7,2 \%$, dengan kriteria efektif berarti media yang telah diuji coba efektif dugunakan dalam proses pembelajaran . Media dikatakan efektif menurut Khoiriyah \& Sari (2018) dan Baiduri et al., (2019) hasil belajar siswa tuntas memperoleh nilai $\geq 75$ dengan presentase ketuntasan $\geq 75 \%$.

Analisis data menyatakan bahwa media pop up book berbasis discovery learning dalam pembuktikan luas dan keliling lingkaran valid, praktis dan efektif. Saran dan perbaikan dari guru matematika bahwa memperbaiki pada halaman 2 seperti tampak pada pada Gambar 1. dan Gambar 2. Perbaikan pada halaman 6 seperti tampak pada Gambar 3. dan Gambar 4.

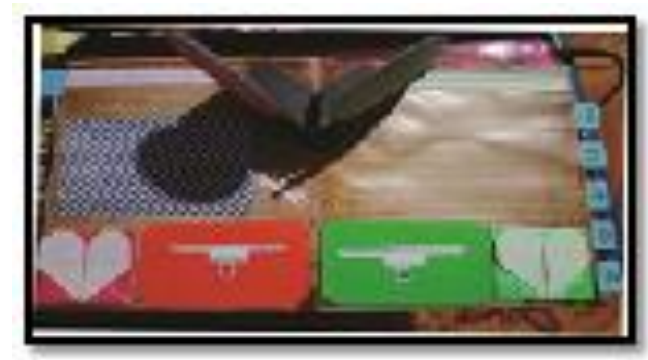

Gambar 1. Halaman 2 sebelum direvisi

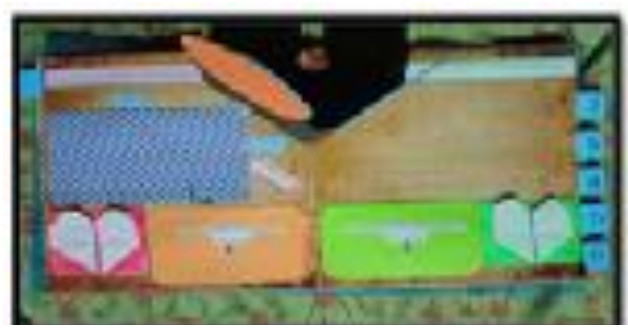

Gambar 2. Halaman 2 sesudah direvisi

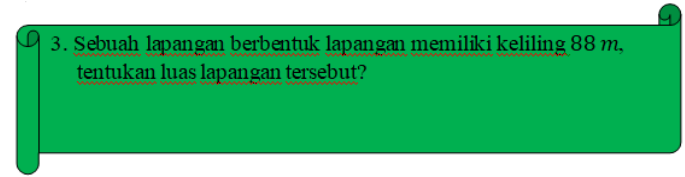

Gambar 3. Halaman 6 sebelum direvisi

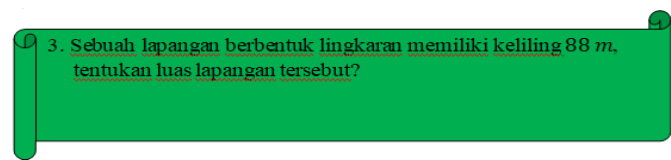

Gambar 4. Halaman 6 setelah direvisi

\section{Hasil Pengembangan}

Gambar 5 menunjukkan sampul pop up book bagian depan dan belakang.

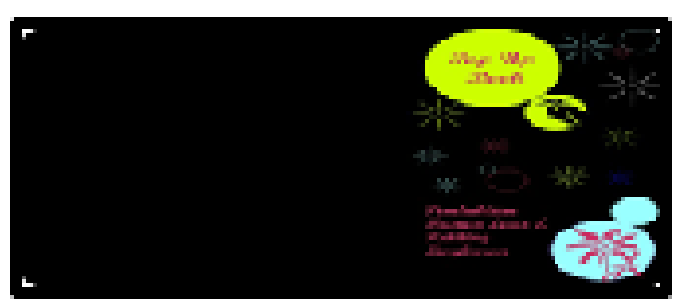

Gambar 5. Sampul pop up book

Sampul dibuat gelap agar tidak terlalu mencolok yang cocok untuk siswa SMP kelas VIII dengan warna tulisan yang warna warni. Halaman pertama pada media pop up book berbasis discovery learning disajikan daftar isi yang dibuka dengan cara ditarik, dan ada tempat amplop kotak yang berisi tujuan pembelajaran dan petunjuk penggunaannya seperti Gambar 6.

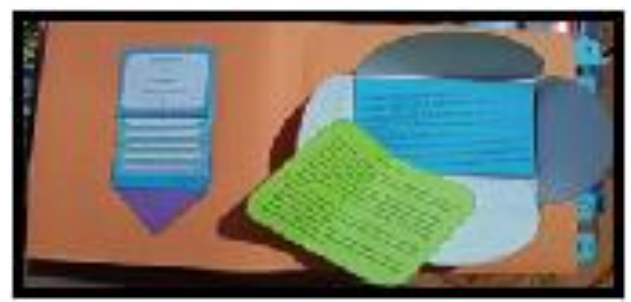

Gambar 6. Daftar isi, petunjuk penggunaan media, \& tujuan pembelajaran

Kertas tujuan pembelajaran dan petunjuk penggunaan media diberi warna yang berbeda supanya pengguna tidak bingung membacanya. Halaman ke 2 terdapat langkah-langkah kegiatan dalam membuktikan rumus luas dan keliling lingkaran. Gambar 7 merupakan pembuktian rumus luas lingkaran dengan warna orange sedangkan pembuktian rumus keliling 
lingkaran bewarna hijau, di media pop up book berbasis discovery learning siswa di suruh membaca langkah yang ada dalam amplop kotak love sesui warna dan tujuan pembuktian.

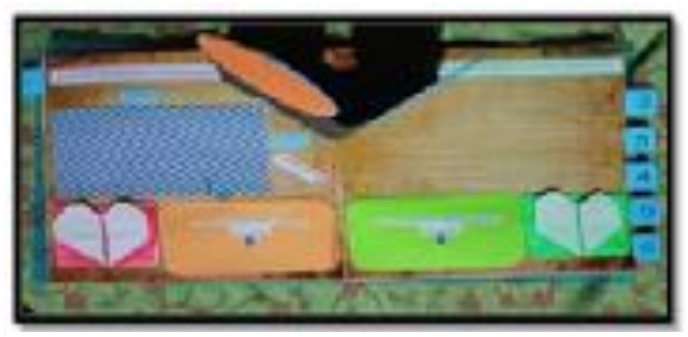

Gambar 7. Pembuktian luas dan keliling lingkaran

Selanjutnya pada halaman 3 terdapat kesimpulan dari kegiatan halaman 2, siswa diharapkan menulis kesimpulan dari kegiatan yang dlakukan. Disajikan seperti pada Gambar 8.

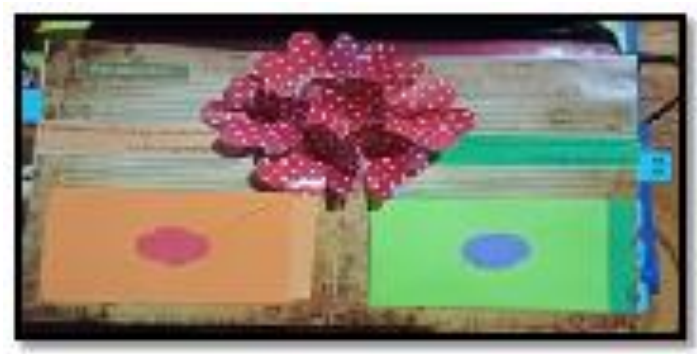

Gambar 8. Kesimpulan

Halaman 4 disajikan contoh soal berupa soal kontektual yang dapat memberikan siswa informasi tentang cara menyelesaikan soal luas dan keliling lingkaran seperti ditunjukkan pada Gambar 9.

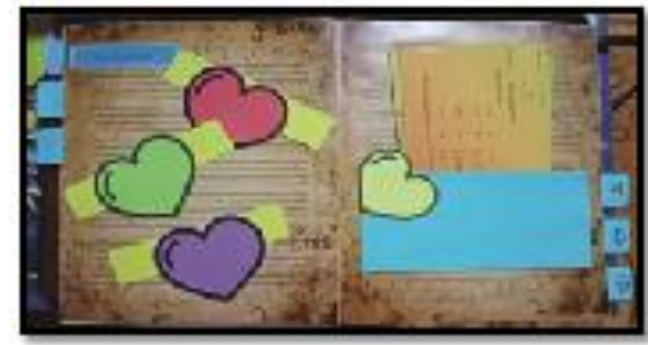

Gambar 9. Contoh soal
Contoh soal bertema love agar menarik siswa. Halaman 5 disajikan dengan balon udara yang memiliki latihan soal. Siswa diharapkan mengerjakan latihan soal, serta jawaban di sajika dengan model temuan terbimbing sehingga siswa tinggal mengisi titik-titiknya kurang lebih seperti Gambar 10.

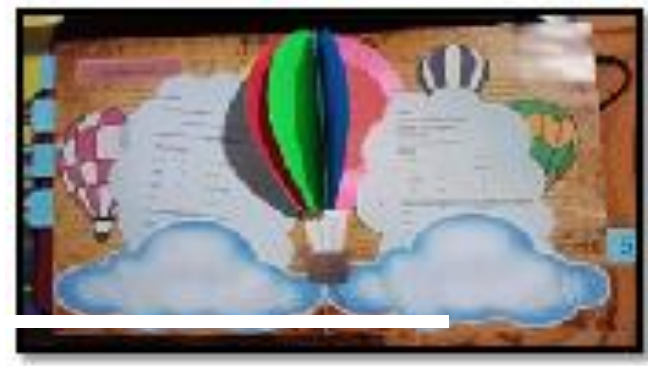

Gambar 10. Soal evaluasi

Soal evaluasi terdapat pada halaman ke 6 dimana di halaman ini menjadi Instrumen tes untuk mengukur keefektifan. Diharapkan jawaban diletakkan pada satu lembar kertas. Soal di letakkan dalam amplop warna warni. disajikan seperti Gambar 11.

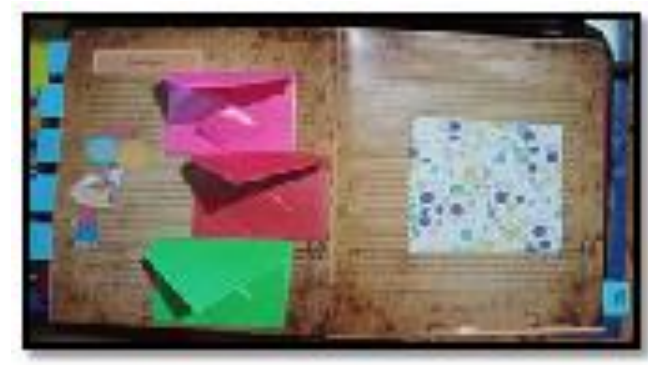

Gambar 11. Evaluasi

Media pembelajaran memperhatikan kebutuhan biaya relatif terjangkau, waktu tidak lama pembuatanya dan daya tahan media. Kelemahan pada media ini, seperti: 1) diharuskan mempunyai keterampilan tinggi pada pembuatannya, misalnya keterampilan melipat kertas; 2) membutuhkan biaya yang cukup banyak; 3) pembuatan yang cukup lama 
sehingga perlu proses panjang; dan 4) media mudah rusak jika terkena air.

Penggunaan teknologi dalam pembelajaran mempermudah memahami konsep, pemecahan masalah dan membuat siswa mandiri. Siswa untuk mendapatkan konsep melakukan percobaan terlebih dahulu (Jana \& Fahmawati, 2020). Inovasi dalam Teknologi pembelajaran dapat memberikan respon yang berbeda pada setiap pada peserta didik dalam menerima materi pelajaran (Ambar Setyomurni dkk., 2019) Pemanfaatan teknologi dengan menyajikan media pembelajaran matematika untuk membantu siswa mempermudah memahami konsep dan memecahkan masalah (Baiduri dkk., 2019)

Hasil uji coba pengembangan media pembelajaran pop up book berbasis discovery learning ini temuan yang menarik antara lain (1) Media pop up book membuat siswa lebih mudah memahami materi luas dan keliling lingkaran yang disajikan gambar secara visual (tiga dimesi). Hal ini sejalan dengan penelitian Oktaviana dkk (2020) bahwa media pop up book membuat siswa dapat dengan mudah memahami materi dan menemukan hasil jawaban soal yang diberikan karena disajikan gambar yang berbentuk visualisasi. Kesulitan pembelajaran berbasis tiga dimesi bisa diminimalkan dengan menggunakan suatu media pop up book (Susilo dkk., 2018)

Hasil temuan (2) selama pembelajaran siswa dalam pembelajaran sangat bersemangat karena media pembelajaran pop up book berbasis discovery learning menuntut siswa untuk aktif dalam pembelajaran, sehingga kemampuan penalaran dan pemecahan masalah siswa berkembang. Hal ini sejalan dengan penelitian Widya dkk.(2020) Pop Up Book efektif digunakan untuk meningkatkan kemampuan penalaran matematis siswa kelas VII.

Media pembelajaran pop up book berbasis discovery learning dalam penyusunannya, disajikan dalam bentuk benda bergerak, sehingga siswa dapat mengetahui proses dari mulai awal sampai akhir penurunan rumus keliling dan luas lingkaran, sehingga kemampuan berfikir siswa untuk menyederhanakan suatu permasalahan sulit akan muncul. Media pembelajaran pop up book berbasis discovery learning ini, siswa dapat mengkonstruk pemahamannya sendiri. Media pop up book berbasis discovery learning ini membuat siswa dapat memahami asal pendekatan rumus keliling dan luas lingkaran. Pendekatan mencari rumus keliling dan luas lingkaran ini dapat membuat kemampuan pemecahan masalah siswa lebih baik. Hal ini sesuai dengan pendapat Amalia dkk (2020) menyatakan bahwa pop up book memiliki efek sangat kuat dalam meningkatkan kemampuan pemecahan masalah matematis siswa. Menurut Putra \& Amalia (2020) pembelajaran discovery learning berbasis assessment learning dapat meningkatkan kemampuan berpikir kritis mahasiswa. Siswa dapat belajar mandiri dapat menggunakan pembelajaran guided discovery (Lu'luilmaknun \& Wutsqa, 2018). Hasil penelitian ini berimplikasi terhadap pemilihan media pembelajaran yang menyenangkan dan memudahkan siswa memahami bangun datar khususnya dalam membuktikan rumus luas dan keliling lingkaran, sehingga siswa dapat menelusuri asal mula penurunan rumus luas dan keliling lingkaran. 


\section{KESIMPULAN DAN SARAN}

Peneliti ini telah menghasilkan sebuah pop up book berbasis discovery learning pada pembuktian luas dan keliling lingkaran yang praktis dan efektif. Temuan penelitian ini media mudah dibawa dan sangat menarik penggunanya, karena dapat berubah bentuk dari 2D menjadi 3D. Model pembelajaran pop up book berbasis discovery lerning membuat siswa sering melakukan eksperimen dan dapat menyimpulkan hasil temuannya. discoveri learning me yang dilakukan.

Perlu dikembangkan lagi untuk penelitian lanjutan bahan ajar matematika berbasis discovery learning berbantuan Pop Up Book dirancang dalam bentuk digital, sehingga pemanfaatannya bisa lebih luas dengan biaya yang relatif murah. Bahan ajar matematika berbasis discovery learning berbantuan Pop Up Book bisa menggunakan software Geogebra atau atau Pembelajaranya dirancang dalam Augmented Reality (AR).

\section{DAFTAR PUSTAKA}

Amalia, N., Darma, Y., \& Wahyudi, W. (2020). Pengembangan Pop Up Book SMP berbasis Ideal Problem Solving untuk Meningkatkan Kemampuan Pemecahan Masalah Matematis. 1(1), 389-398.

Ambar Setyomurni, R., Putra, R. P., \& Qomariyah, L. (2019). NusTrick (Muslihat Nusantara) Pengembangan Media Pembelajaran Berbasis Game Terhadap Pemahaman Konsep Pola Bilangan. Pi: Mathematics Education Journal, 2(1), 1-6. https://doi.org/10.21067/pmej.v2 i1.2536

Baiduri, B. B., Taufik, M.-, \& Elfiani, L.-. (2019). Pengembangan
Media Pembelajaran Pop-Up Book Berbasis Audio Pada Materi Bangun Datar Segiempat Di Smp. AKSIOMA: Jurnal Program Studi Pendidikan Matematika, $\quad 8(1)$. https://doi.org/10.24127/ajpm.v8 i1.1951

Baiduri, B., Taufik, M., \& Elfiani, L. (2019). Pengembangan Media Pembelajaran Pop-Up Book Berbasis Audio Pada Materi Bangun Datar Segiempat Di SMP. Aksioma Jurnal, 8(1), 248-261.

Batubara, I. H. (2020). Pengaruh Model Pembelajaran Guided Discovery Learning terhadap Hasil Belajar Pengembangan Silabus Pembelajaran Matematika pada Masa Pandemic Covid 19. Jurnal Penelitian, Pendidikan Dan Pengajaran: JPPP, 1(2), 13-17.

Devi, A. S., \& Maisaroh, S. (2017). Pengembangan Media Pembelajaran Buku Pop-Up Wayang Tokoh Pandhawa pada Mata Pelajaran Bahasa Jawa Kelas V SD. Jurnal PGSD Indonesia, 3(2).

Fitriyah, S. (2018). The Effectiveness of Problem Based Learning Pop Up Book to the Mathematic Students Ability on Problem Solving Class VIII. Kontinu: Jurnal Penelitian Didaktik Matematika, 1(1), 72-87.

Hendri, S., \& Kenedi, A. K. (2018). Pengembangan perangkat pembelajaran matematika berbasis discovery learning untuk meningkatkan kemampuan pemecahan masalah siswa kelas VIII SMP. Jurnal Inspirasi Pendidikan, 8(2), 1024. 
Ikbal, M. S., Rafiqah, R., \& Khuzaimah, A. U. (2020). Pengembangan Modul Pembelajaran IPA Fisika Berbasis Pop-up Book. Jurnal Pendidikan Fisika, 8(1), 53-60.

Jana, P., \& Fahmawati, A. A. N. (2020). MODEL Discovery Learning Untuk Meningkatkan Kemampuan Pemecahan Masalah. AKSIOMA: Jurnal Program Studi Pendidikan Matematika, 9(1), 213. https://doi.org/10.24127/ajpm.v9 i1.2157

Khoiriyah, E., \& Sari, E. Y. (2018). Pengembangan Media Pembelajaran Pop-Up Book Pada Mata Pelajaran Ipa Kelas Iii Sdn 3 Junjung Kecamatan Suymbergempol Kabupaten Tulungagung. Jurnal Bidang Pendidikan Dasar, 2(2), 22-32.

Kusrianto, S. I., Suhito, S., \& Wuryanto, W. (2016). Keefektifan Model Pembelajaran Core Berbantuan Pop Up Book Terhadap Kemampuan Siswa Kelas Viii Pada Aspek Representasi Matematis. Unnes Journal of Mathematics Education, 5(2).

Lu'luilmaknun, U., \& Wutsqa, D. U. (2018). Efektivitas Media ELearning Dengan Metode Guided Discovery Ditinjau Dari Kemandirian Belajar Matematika Siswa. 7(3), 12.

Murdiyanto, T., \& Mahatama, Y. (2014). Pengembangan alat peraga matematika untuk meningkatkan minat dan motivasi belajar matematika siswa sekolah dasar. Sarwahita, 11(1), 38-43.

Oktaviana, D., Prihatin, I., \& Fahrizar, F. (2020). Pengembangan Media Pop-Up Book Berbasis
Contextual Teaching And Learning Dalam Pencapaian Kemampuan Pemecahan Masalah. AKSIOMA: Jurnal Program Studi Pendidikan Matematika, 9(1), 1-11.

Permana, E. P., \& Sari, Y. E. P. (2018). Development of Pop Up Book Media Material Distinguishing Characteristics of Healthy and Unfit Environments Class III Students Elementary School. International Journal of Elementary Education, 2(1).

Putra, E. D., \& Amalia, R. (2020). Upaya Meningkatkan Kemampuan Berpikir Kritis Mahasiswa Melalui Pembelajaran Discovery Learning Berbasis Assessment Learning. Journal of Education and Learning Mathematics Research (JELMaR), 1(1), 5764.

Ramdhani, M. A., \& Muhammadiyah, H. (2015). The criteria of learning media selection for character education in higher education.

Safri, M., Sari, S. A., \& Marlina, M. (2017). Pengembangan media belajar Pop-up Book pada materi minyak bumi. Jurnal Pendidikan Sains Indonesia (Indonesian Journal of Science Education), 5(1), 107-113.

Susilo, T., Sujadi, I., \& Indriati, D. (2018). Developing A Media 'Visual Design of Pop Up Mathematics Book'as a Supporting Tool in InquiryBased Learning for Learning Three-Dimensional Figures. $1108(1), 012029$.

Sutarka, I. W. (2020). Implementasi Model Pembelajaran Discovery Learning Melalui Media 
DOI: https://doi.org/10.24127/ajpm.v10i2.3091

Classroom Dalam Pembelajaran Materi Tri Guna Bagi Siswa Kelas VIII SMPN 1 Parigi Pada Masa Pandemi Covid-19. Cetta: Jurnal Ilmu Pendidikan, 3(3a1).

Svinicki, M. D. (1998). A theoretical foundation for discovery learning. Advances in Physiology Education, 275(6), S4.

Widya, P. N., Ariyanto, L., \& Murtianto, Y. H. (2020). Pengembangan Bahan Ajar Matematika Berbasis Contextual Teaching and Learning Berbantuan Pop Up Book untuk Meningkatkan Kemampuan Penalaran Matematis Siswa Kelas VII. Imajiner: Jurnal Matematika Dan Pendidikan Matematika, 2(2), 95-101. 